\title{
A ENFERMAGEM E O SISTEMA DE EDUCAÇÃO PRÉ-PRIMÁRIA
}

\author{
Lenira Fontenele Sampaio Perdigão
}

$(*)$

\section{INTRODUÇÃO:}

As instituições do sistema de educação pré-primária são tradicionalmente representadas em nosso meio (1) por:

a) creche ou pupileira, para crianças de 0 a 2 anos de idade;

b) escola maternal, para idades de 2 a 4 anos;

c) jardım de infância, para crianças entre 4 e 6 anos.

Termos como "infant school" (Inglaterra); "nursery school' (EEUU); "créche" ou "école maternelle" (França); "casa dei bambini" (Italia); "Kindergarten" (Alemanha e EEUU), têm sido utilizados internacionalmente, nem sempre baseados em definições precisas.

Os primeiros estabelecimentos tinham conotação filantrópica e religiosa, com a finalidade básica de substituir cuidados propiciados nos lares a crianças abandonadas ou cujas mães não podiam assistí-las. O progresso da medicina, picologia e educação, contribuindo para melhor compreensão da criança, no que se refere ao seu desenvolvimento físico, segurança emocional, evolução social e educativa, determinou uma evolução conceitual dessas instituições do sistema de educação pré-primária.

Hodiernamente, constituem elas uma necessidade social, face a razões ligadas à posição da mulher no atual sistema de vida, com redução das funções inerentes ao papel materno no lar por:

(*) Enfermeira do quadro da Secretaria de Saúde do Estado do Ceará, em exercício na Fundação do Bem-Estar do Menor. 
- falta de aptidões ou incapacidade;

- deficiente formação da personalidade;

- falta de possibilidades materiais ou de tempo por questões financeiras ou de trabalho.

Atualmente as instituições de educação pré-primarıa têm como meta específica a formação integral da criança, vetorizada nas suas finalidades básicas:

a) recuperação, proteção e promoção da saúde;

b) desenvolvimento cívico, moral, social e espiritual;

c) educação dos sentidos e a formação da personalidade;

d) formação de capacidade e interesse estético.

Dada a importância da participação dos pais e dos grupos da comunidade na formação integral da criança, a educação dos pais e desses grupos constitue igualmente outra meta a ser atingida.

Um programa eficiente (2) terá apoio na tríade: saúde física + higiene mental + estímulo intelectual das crianças, como suplemenação das atenções recebidas nos seus respectivos lares:

\section{BASES DA PROGRAMAÇÃO DO SISTEMA DE EDUCAÇÃO PRÉ-PRIMÁRIA}

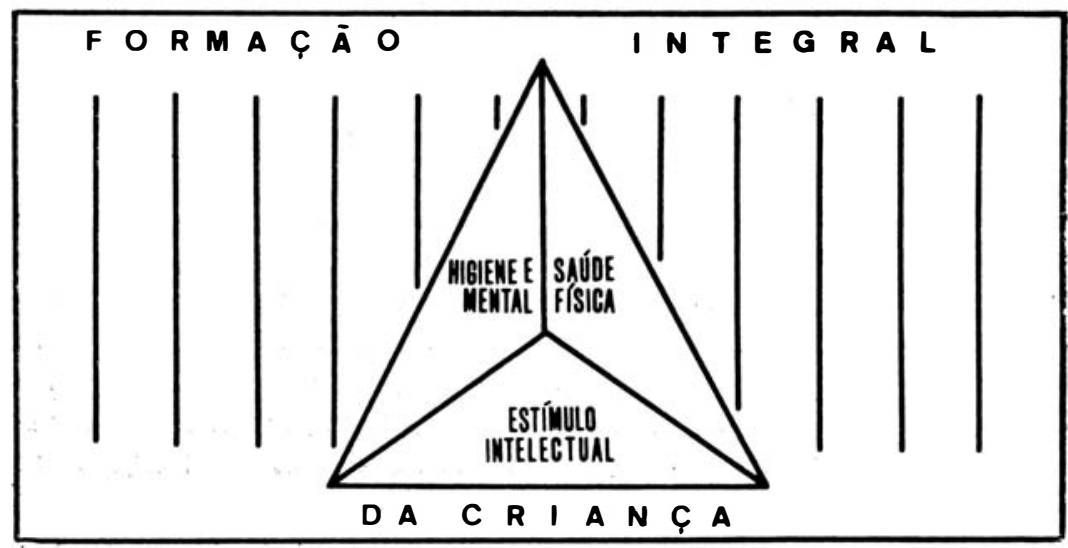

II. PAPEL DA ENFERMAGEM:

Envolve ações específicas de enfermagem, aliadas ao estabelecimento de um sistema de integração com outras áreas profissionais. Compreende as seguintes ações: 


\section{TRIAGEM:}

A inspeção preliminar das crianças, por ocasião da admissão em estabelecimentos do sistema, é uma fase de grande responsabilidade, cevido às imp’icações representadas pela introdução de doentes (sobretudo com doença transmissível) em comunidade infantil sadia.

Em centros de triagem ou nos locais onde permanecem as crianças, a inspeção é feita como prévia à admissão diária, selecionando os casos que deverão ser agendados mediata ou imediatamente, para consulta médica e/ou odontológica.

Basicamente, a inspeção compreende:

a) visão geral do tegumento, pesquisando lesões, particularmente aquelas que lembrem processos transmissíveis;

b) observação da garganta e vias aéreas superiores em busca de alterações inflamatórias ou de suas consequências;

c) o mesmo, com relação a olhos, ouvidos e narinas;

d) aferição da temperatura corporal.

As ações poderão ser desenvolvidas por pessoal de enfermagem nível auxiliar ou por professores, sob supervisão e orientação específica da enfermeira supervisora.

\section{ORIENTAÇÃO DO AMBIENTE DE TRABALHO:}

As atividades desenvolvidas no ambiente físico de trabalho sob administração técnica da enfermeira são:

a) aconselhar a manutenção e utilização das condições de ventilação, iluminação, proteção contra ruidos, contra acidentes e demais condições que satisfaçam as necessidades fundamentais da criança, fisiológicas e psicológicas;

b) manter, em condições satisfatórias, a apresentação pessoal e disciplina técnica de trabalho do pessoal subalterno da área da saúde;

c) assegurar condições funcionais do equipamento, material permanente e de consumo para saúde;

d) orientar limpeza e manutenção das instalações, defesa contra insetos e roedores, organização e utilização da rouparia e de utensilios ligados à assistência infantil no que se refere à prevenção de doenças transmissíveis; 
e) proporcionar atenção direta à criança, consequente à orientação médica, ou na prestação de socorros de urgência.

\section{ATIVIDADES COMUNITÁRIAS:}

De responsabilidade direta da enfermeira, dão uma nova dimensão ao sistema, visando sinteticamente:

a) manter a comunidade informada acerca das finalidades e funcionamento dos estabelecimentos;

b) educar os pais e grupos comunitários no que se refere à saúde física e mental da criança, as medidas profiláticas contra as doenças e a importância do registro de nascimento;

c) levantar as condições do meio ambiente ("sensu latu") em que vive a criança, capazes de influenciar seu desenvolvimento e sua concepção da sociedade.

\section{PROGRAMA DE TRATAMENTO DE PESSOAL:}

Sob a responsabilidade da enfermeira, esse deve ser desenvolvido não somente para o pessoal de enfermagem como também para 0 corpo docente e componentes de outros grupos profissionais pertencentes ao sistema.

E igualmente importante a participação da enfermeira, no processo de seleção das pessoas que trabalharão diretamente com as crianças a fim de ajudá-las desenvolver atitudes adequadas com relação aos infantes. No processo de seleção, é indispensável que a enfermeira observe se essas pessoas demonstram:

a) apreciar o convívio com crianças;

b) ser pacientes e compreensivas;

c) poder dar e receber satisfação do seu trabalho;

d) boa saúde;

e) urbanidade no tratamento de pais e crianças;

f) possuir espírito de iniciativa;

g) capacidade de trabalhar harmonicamente com outros profissionais;

O conteúdo do programa de treinamento deve incluir noções sobre:

- crescimento e desenvolvimento da criança normal;

- fisiopatologia infantil (sistemas de agressão e de defesa);

- técnicas e táticas da assistência infantil. 
O treinamento deverá ser mantido em processo contínuo, com atualizações frequentes, não dispensando as ajudas audiovisuais e os exercícios práticos.

\section{ATIVIDADES ASSISTENCIAIS PROPRIAMENTE DITAS:}

Cabe à enfermeira supervisora orientar e supervisionar o desenvolvimento de:

a) programa de imunizações:

CRONOGRAMA DE VACINAÇÕES

\begin{tabular}{|c|c|c|c|c|c|c|c|c|c|c|c|c|}
\hline \multirow[t]{2}{*}{ DOENCAS } & \multirow{2}{*}{$\begin{array}{l}\text { TIPOS DE } \\
\text { VACINAS }\end{array}$} & \multirow{2}{*}{$\begin{array}{l}\text { ESQUEMAS UTI- } \\
\text { LIZADOS }\end{array}$} & \multicolumn{8}{|c|}{ MESES } & \multicolumn{2}{|c|}{ ANOS } \\
\hline & & & 12 & 22 & 32 & 42 & 62 & 92 & $102 / 112$ & 162 & 52 & 62 \\
\hline Tubercu - & BCG oral & Primovocinog 80 & & & & & & & & & & \\
\hline lose & BCG I. D. & Revocinoģoo & & & & & & & & & & \\
\hline Dift. Tét. & DTP & Pr I movocinocgoo & & & & & & & & & & \\
\hline Coqueluche & $"$ & Reforço & & & & & & & & & & - \\
\hline Térano & AnT & Reforgo & & & & & & & & & & \\
\hline Varlola & AV & Primovocinoçdo & & & & & & & & & & \\
\hline & 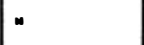 & Revocinoggoo & & & & & & & & & & \\
\hline Poliomie- & Sobln & Primovocino ģఠo & & & & & & & & & & \\
\hline lite & & & & & & & & & & & & \\
\hline
\end{tabular}

As revacinações e reforços deverão ser feitas antes da criança abandonar o sistema pré-pimário, para que possa enfrentar com maiores chances, as doenças prervalentes no meio escolar.

b) educação da saúde:

Ministrada diretamente à criança ou indiretamente através do corpo docente, o programa de educação da saúde deve visar:

- formação de habitos de higiene pessoal que incluem higiene cio vestuário, alimentação e sono, exercício e recreação;

- desenvolvimento de boas maneiras;

— prevenção de acidentes. 
c) saúde infantil:

Tem como objetivo manter o estado de higidez da criança, constituindo basicamente em:

- acompanhar o desenvolvimento ponderal, estatural e dos órgãos dos sentidos, agendando consultas médicas e/ou odontológicas, nos desvios da normalidade;

- cooperar na realização de examos complementares de diagnóstico e tratamento;

- propor meios para evitar o desenvolvimento de deformidades posturais e de deficiência dos ógãos dos sentidos.

As atenções dedicadas à criança apresentam o seguinte encaixe, na rotina diária:

MODÊLO DE ROTINA DIÁRIA NOS ESTABELECIMENTOS COM SEMI-INTERNATO

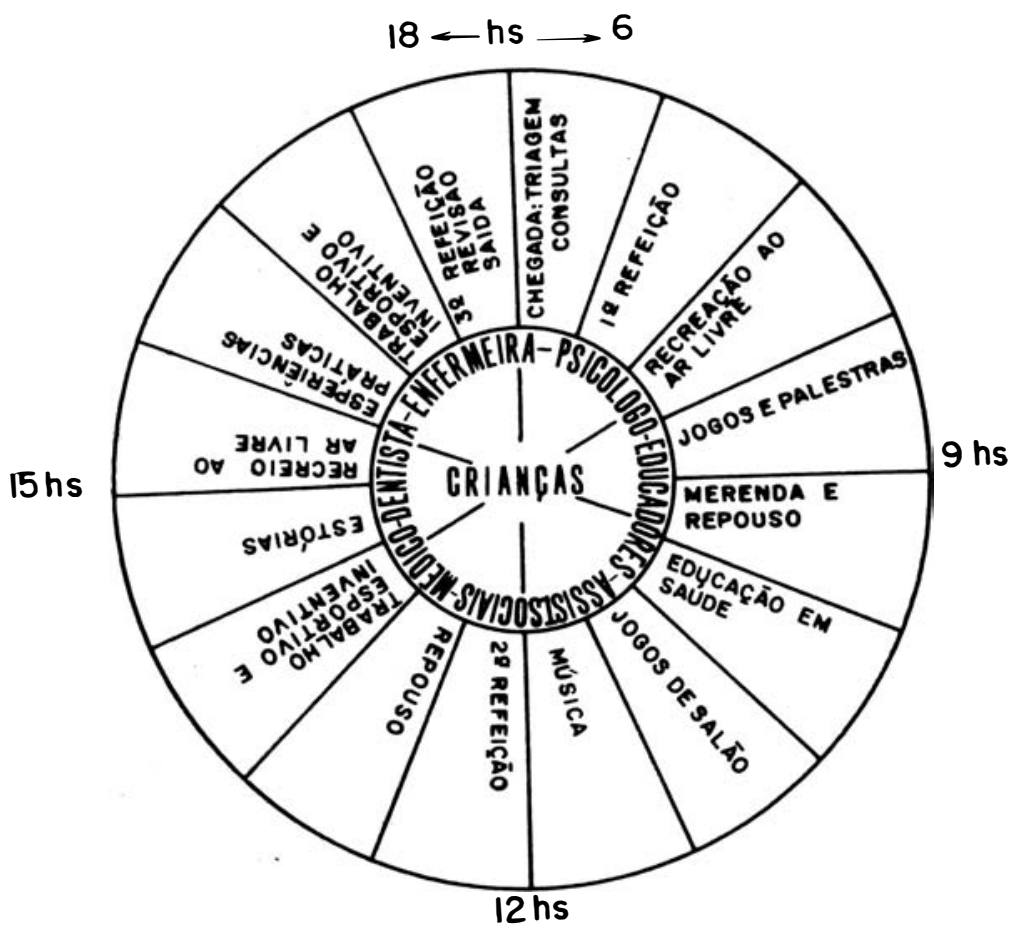




\section{INTEGRAÇÃO:}

Uma constante em todo o processo deve ser o entrosamento no processamento da ação com educadores, psicólogos, assistentes sociais, etc. já que inexistem tarefas estanques. A expressão dessa integração pcderá traduzir-se na utilização de um prontuário único, donde se possa extrair um conceito global sobre a criança. Reuniões multiprofissionais periódicas poderão ser realizadas, para prática e aperfeiçoamento do entrosamento. A resultante da aplicação destes princípiois, será uma assistência eficiente e continuada.

\section{A AVALIAÇ̃̃O}

Constituem elementos de avaliação do sucesso do empreendimento:

a) com relação à criança:

- desenvolvimento motor, do intelecto e da linguagem;

- desenvolvimento social, emocional e da personalidade;

b) com relação ao ambiente familiar:

- melhoria das relações pais-filhos.

\section{CONCLUSÕES:}

1. A participação da profissional de enfermagem no sistema de educação pré-primária tem como objetivo a prestação de assistência integral à criança e se a licença na supervisão do seu crescimento e desenvolvimento.

2. Para tanto, devem ser empreendidas ações de enfermagem, sob a forma de cuidados diretos à criança, triagem para atenção médica e/ou odontológica e ações comunitárias, sob supervisão de enfermeira.

3. Todas as ações se desenvolverão sob a forma de interação multi-profissional e serão avaliadas por índices relacionados ao desenvolvimento infantil e modificações do habitat da criança.

\section{REFERENCIAS:}

HUNTINGTON, D. S.: "Experience with hairing - staff of infant care programs". A.J.P.H. 62(1): 46-49, jan. 1972.

LEA.VITT, J. E. et alii: "Nursery Kindergarten education"”. Mc-Graw-Hill, 1958.

MEDINA, A. : “Educación de Párvulos”. Edit. Labor S/A, 3." ed. 1967.

NINA, C. A. : "Escolas Maternais e Jardins de Infância”. DNCr, 2 ed., 1955. 